Journal of Engineering Sciences, Assiut University, Vol. 37, No. 5, pp. 1081-1097, September 2009.

\title{
INVESTIGATION ON DIFFERENT LATERAL EARTHQUAKE FORCE METHODS OF ANALYSIS
}

\author{
Waleed Abo El-Wafa Mohamed \\ Lecturer, Civil Engineering Department, Faculty of Engineering, Assiut \\ University, Assiut, Egypt.
}

(Received August 6, 2009 Accepted August 24, 2009).

In the concept of lateral seismic design there are three famous analysis methods. These methods include the equivalent static load (ESL), modal response spectrum (MRS) and time history analysis (THA). In this study, the variation in the resulted base shear using any of these methods is investigated. The modal response spectrum analysis, either simplified (same as ESL) or multiple, is carried out using the elastic design spectrum specified by the renewed Egyptian Code of Loads (2008 ECOL). The time history analysis is applied using seven delibrate different real earthquake excitations selected to match the specified elastic spectrum and soil type. Suggestions to rationally enhance the seismic protection level obtained from the multiple response spectrum is presented and emphasized. This study extends to analyze and compare our resulted base shear with those obtained from different international codes as the European, American and Canadian codes for sites with similar conditions. Special emphasis is paid to evaluate the ECOL response modification factors compared with the considered codes. It is found that there is high variation between the base shear obtained using the code specified different analysis methods and in comparison with the considered codes and hence some seismic provisions in the new 2008 ECOL need to be recontemplated.

KEYWORDS: Seismic codes, ECOL, seismic analysis methods, response modification factor.

\section{INTRODUCTION}

Earthquake tremors usually induce loads which trigger the structure to respond in such a dynamic phenomenon which depends on the intensity, duration, and frequency content of the exciting motion as well as the dynamic characteristics of structures. Building codes recommend using either equivalent load method, due to its simplicity, or multi modal response spectrum method. Time history analysis, either linear or nonlinear, is usually an optional method. The use of static load analysis in establishing seismic design quantities is justified because of the complexities associated with dynamic analysis. Although the ability to carry out nonlinear analysis has seen significant improvement recently, considerable uncertainty arises in modeling the nonlinear behavior of structural materials and components. In addition, nonlinear response to two different ground motions may differ significantly. In view of the difficulties associated with nonlinear analysis, linear dynamic analysis is often carried out to determine the design forces. Computer programs that are capable of carrying out a linear dynamic analysis, either a time-history or a multi modal response analysis, are 
widely available recently, and designers are becoming increasingly comfortable in using them.

The seismic provisions in the Egyptian code of loads ECOL, in all its editions [1] - [3], specify three different methods to get the design base shear which are modal response spectrum analysis MRS, either simplified or multi-modal, and the dynamic time history analysis THA. However, the limitations of using each of these methods vary between the 1993 edition and the later two ones. According to the later editions of 2008 ECOL, multi MRS and THA are valid to be utilized for all types of structures but with some conditions related to THA. The equivalent load method, referred to as simplified MRS in 2008 ECOL, is still applicable in many cases. However, using this method to determine the design base shear faces many restrictions in this edition concerning with the structural system regularity and the relation between building fundamental period and the code specified elastic response spectrum.

National building seismic codes and their provisions always gain a specific concern from researchers especially with the continuous development in these codes. Many clear research examples can be mentioned as the seismic design forces specified by the National Building Code of Canada NBCC [4] as in [5] and [6]. Comparative studies between national seismic provisions and international ones as Turkish earthquake code and $U B C$ [7] as [8], Eurocode-8 [9] and Japanese one as [10] and comparison between set of different international codes as [11] were also reported. The response modification factor, may has different denominations, in many national codes attracted much attention as in [12], [13] and [14] which were concerned with Eurocode-8, UBC and Chinese codes, respectively. Egyptian researchers have also paid much attention to the seismic provisions in the previous ECOL editions in many subjects as suggested code fundamental period equations [15] and [16], performance and ductility [17] and nonstructural elements [18] and [19]. The seismic provisions in the recently renewed 2008 ECOL were also overviewed and discussed [20].

This analytical investigation comes to pursue a specific aspects of the recently presented seismic provisions in the 2008 ECOL. Thus the objectives of the present investigation hold the followings: (i) to investigate and compare the lateral base shear resulted from the different analysis methods specified in the recent edition of the 2008 ECOL; (ii) to analytically compare our resulted base shear with those calculated from codes of different countries as Eurocode-8, UBC 97 and $N B C C$ for similar conditions and finally (iii) to pay a particular emphasis to evaluate the $E C O L$ response modification factors compared with considered codes. To achieve these goals, the modal response spectrum analysis, either simplified or multiple, is carried out using the elastic response spectrum specified in the codes under considerations. The possible reductions that can be done due to the expected inelastic seismic behavior of buildings are to be considered according to each code provisions. The THA is applied using seven deliberate earthquake excitations match the 2008 ECOL specified provisions for Cairo city with similar soil conditions. The selected earthquakes are real ones and shock four continents in the globe at different periods. Two widely used building types are used in the analytical investigation which are moment resisting frames MRF and dual shear wall moment resisting frames SW-MRF buildings with wide range of different heights. Both regular and irregular buildings are used in this investigation. Possible analysis enhancements are discussed. 


\section{DIFFERENT ANALYSIS METHODS IN 2008 ECOL}

The modal response spectrum analysis, either simplified or multiple, in the 2008 ECOL is carried out relying on the specified elastic response spectrum which is adopted depending on the location of the city. Two response spectrum are presented by this code, the first suits all regions in Egypt while the second suits coastal cities along the Mediterranean sea and extends for forty kilometers parallel to the shore. Fig. 1 depicts Type (1) elastic response spectrum noting that Type (2) spectrum carries the same features as Type (1) except for the governing period values $\left(\mathrm{T}_{\mathrm{B}}, \mathrm{T}_{\mathrm{C}}\right.$ and $\left.\mathrm{T}_{\mathrm{D}}\right)$. The 2008 ECOL permits the structural design according to seismic loads less than what can be obtained from the elastic response spectrum due to the expected nonlinear behavior of structures. Thus the values of the design response spectrum can be uses and hence the basic base shear (at foundation level) according to the simplified MRS method can be obtained as follows:

$$
F_{b}=S_{d}\left(T_{I}\right) \lambda W / g
$$

In which;

$S_{d}$ is the design response spectrum.

$T_{I}$ is the fundamental period equation in the direction of analysis.

$\lambda$ is a correction factor, is equal to 0.85 if $T_{I} \leq 2 T_{C}$ and is equal to 1.0 if $T_{I}>2 T_{C}$.

$W$ is a total considered weight of the structure and $g$ is the gravity acceleration.

The 2008 ECOL limits the application of simplified MRS analysis to buildings which are regular in both plan and elevation and having fundamental period equal or less than either $4.0 T_{c}$ or $2.0 \mathrm{sec}$. As the values of $T_{c}$ related to spectrum type (1) is either 0.3 for subsoil class D and 0.25 for other soil types, the applicability of this method will be highly restricted to structures having $T$ less than either $1.2 \mathrm{sec}$ or 1.0 sec for the mentioned soil types, respectively. For buildings in regions compatible with type (2) spectrum, at which the values of $T_{c}$ range between 0.4 and 0.8 , the validity of applying this method increases to buildings with maximum fundamental period ranges between 1.4 and 2.0 arranged from soil type A to D.

The multi MRS method is valid in 2008 ECOL to be unconditionally applied to all types of buildings. Time history analysis THA is also permitted for all types of buildings but under some specific conditions. The selected ground motion excitations used in the THA should be compatible with the design response spectrum specified by the code in the critical period range. To consider the maximum response of the selected earthquake excitations a minimum of three records is required. However, seven accelograms are required to consider their average resulting forces. The $2008 \mathrm{ECOL}$ had renewed a condition, that the response obtained from the THA is required not to be less than $80 \%$ of those obtained using multi MRS. It is worth to mention here that in 1993 ECOL edition, and many international codes, the forces obtained from the multi MRS analysis are limited or scaled to those obtained using the simplified MRS method. 


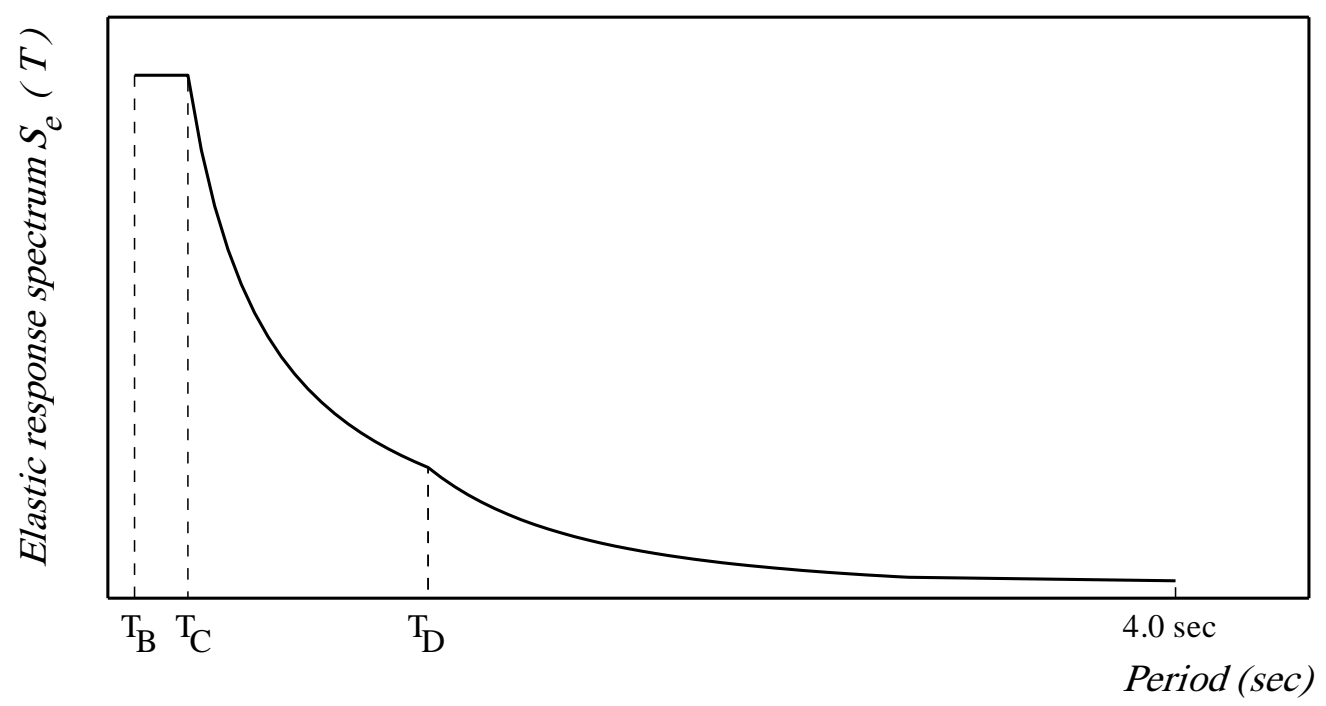

Fig. 1 : Type (1) elastic response spectrum

\section{APPLIED EARTHQUAKE EXCITATIONS}

Seven different ground excitations, shock different five countries, are selected to match the seismicity of Cairo with soil type C. Six of these excitations naturally have maximum scaled spectrum acceleration close to the one calculated for Cairo. The seventh one, Aqba earthquake which shook Egypt in 1998, is scaled to match the seismic requirements for Cairo city. The spectrum accelerations of these quakes along with their abbreviations are shown in Fig. 2 while a brief data for each selected excitation is shown in Table $\mathbf{1}$.

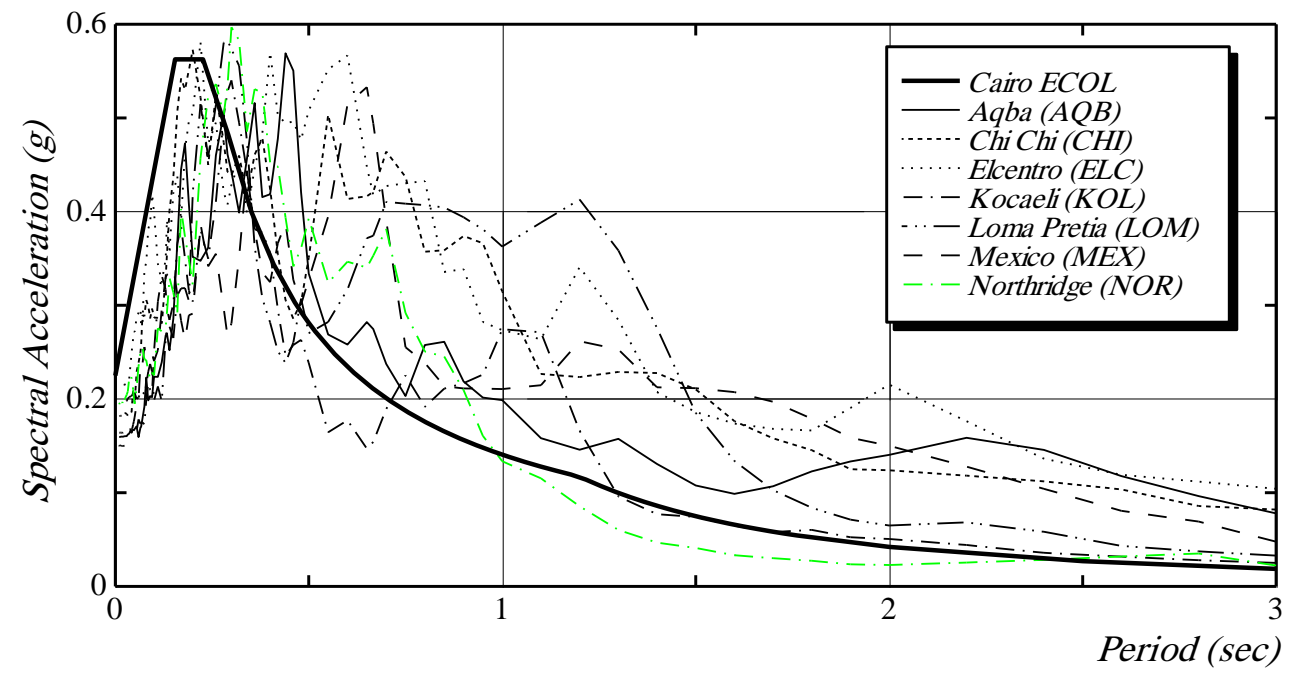

Fig. 2 : Response spectral acceleration of used excitations versus code spectra 
Table 1: Earthquake excitation data

\begin{tabular}{|c|c|c|c|c|c|}
\hline Earthquake & Date & Location & Component & PGA $(\mathrm{g})$ & $\mathrm{S}_{\mathrm{e}}$ \\
\hline Aqba & $22 / 11 / 1995$ & Eilat & EW & 0.097 & 0.569 \\
\hline Chi Chi & $20 / 9 / 1999$ & Taiwan & NS & 0.184 & 0.573 \\
\hline Elcentro & $19 / 5 / 1940$ & Imperial Valley & 270 & 0.215 & 0.581 \\
\hline Koceali & $17 / 8 / 1999$ & Turkey & 090 & 0.164 & 0.540 \\
\hline Loma Pretia & $18 / 10 / 1989$ & Loma Pretia & 000 & 0.226 & 0.583 \\
\hline Mexico & $9 / 6 / 1980$ & Mexico & 102 & 0.15 & 0.533 \\
\hline Northridge & $17 / 1 / 1994$ & Northridge & 330 & 0.194 & 0.597 \\
\hline
\end{tabular}

In the above table the PGA refers to the peak ground acceleration while $S_{e}$ refers to the maximum elastic response spectrum. The maximum elastic response spectrum for buildings located in Cairo city is calculated using the following equation:

$S_{e}(T)=2.5 a_{g} S \zeta \gamma$

In which:

$a_{g}$ is the design earthquake acceleration, $S$ is the soil factor, $\zeta$ is a damping correction and $\gamma$ is the building importance factor.

Hence, for an ordinary R.C building located in Cairo city and founded on basic soil type $\mathrm{C}$, the maximum elastic response spectrum will be equal to 0.5625 .

\section{BUILDINGS USED IN COMPUTER BASE ANALYSIS}

In order to carry out either MRS or THA, two types of regular buildings, MRF and SW-MRF are used. Fig. 3 depicts example of SW-MRF, The MRF building has same plan features while replacing the shear walls with columns. The buildings are square with typical bay dimension of $5.0 \mathrm{~m}$. Different building heights represented by the number of floors are considered, 3, 6, 9, 12, 15 and 17 floor buildings are analyzed. The height of the first floor above foundation is always equal to $4.5 \mathrm{~m}$, while the height of the typical remaining floors are $3.0 \mathrm{~m}$. The column sections are varying according to the height of building. The effective total lengths of shear walls in the first storey in each orthogonal direction $\left(L_{w}\right)$ is seismically designed. This ratio $\left(L_{w} / H\right)$ is 0.20 for each orthogonal direction, $\mathrm{SW}$ thickness is $0.2 \mathrm{~m}$.

For the sake of a specific comparison between 2008 ECOL and Eurocode-8, the building, whose plan is shown in Fig. $\mathbf{4}$ is considered. This building is irregular in plan according to the irregularity criteria specified by both considered codes due to the shown extension. The typical bay dimension is $5.0 \mathrm{~m}$ in each orthogonal direction. Irregularity is also applied in the vertical direction due to setback of the extended part in the last two floors. Different building heights are considered and represented by the 
total number of floors. The considered total number of floors and floor heights are identical to the previously displayed regular building.

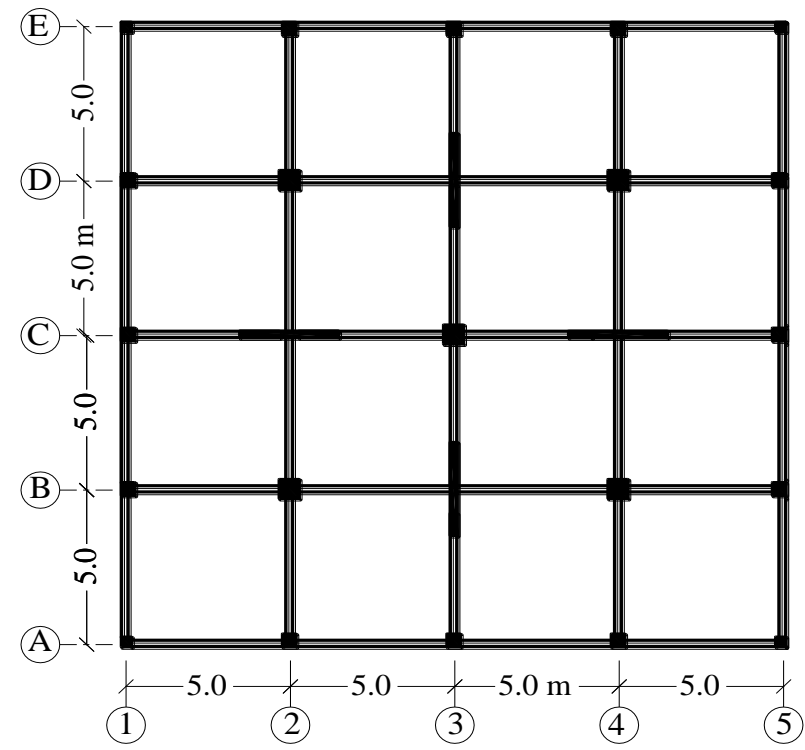

Fig. 3 : Plan of example SW-MRF regular building



Fig. 4 : Plan of the irregular MRF building

The compressive strength of used concrete is $25.0 \mathrm{MPa}$ while the used steel is high tensile with yield strength of $400.0 \mathrm{MPa}$. The analysis is carried out using two software packages ETABS [21] and SAP 2000 [22]. 


\section{BASE SHEAR USING DIFFERENT ANALYSIS METHODS}

The results of multi MRS and dynamic THA, using the indicated seven ground excitations, in comparison with those obtained using the simplified MRS for both MRF and SW-MRF buildings are illustrated in Figs. 5 and 6, respectively. Before discussing the results it is worth to mention that the elastic response spectrum obtained from the different indicated excitations and used for THA are modified to account for the response modification factor. Also, the obtained results from this method, THA, are scaled to be ultimate loads using a factor of 1.4. In case of MRF buildings, the results obtained using the simplified MRS are valid up to height equal to about $31.5 \mathrm{~m}$ according to code limitations which restricts the utilization of this method to $4 T_{c}$, however, for the purpose of comparison, the curve is virtually extended over the whole considered height. As seven excitations are considered in the THA, then the average response of these excitations could be considered, this average is illustrated using the dash line.

Firstly, discussing the results obtained for the MRF, it is clear that, generally, the highest V/W is obtained in the order of, THA, simplified MRS and at last the multi MRS analysis. The V/W obtained utilizing the multi-MRS methods is much less than those obtained using the simplified MRS method over the whole considered building heights. The $\%$ change, related to the simplified MRS method is in the range of $-35.6 \%$ to $-48.8 \%$. The average results obtained from THA are higher than those obtained using simplified MRS method in the height range that compel to the limitation of using the later method. The $\%$ change ranges between $+21.8 \%$ and $-39.7 \%$. In the rest of height range the $\%$ change ranges between $+24.6 \%$ and $-30.8 \%$. It is observed that the results of scaled Aqaba quake, the only one of the considered excitations that shook Egypt are very close to the results of the simplified MRS method. It is worth to mention that, in contrary to the code expectation which limits the results of the THA to the multi MRS analysis, the results of the former method is higher than the later one be a $\%$ change in the range of $+11.4 \%$ to $+138.6 \%$.

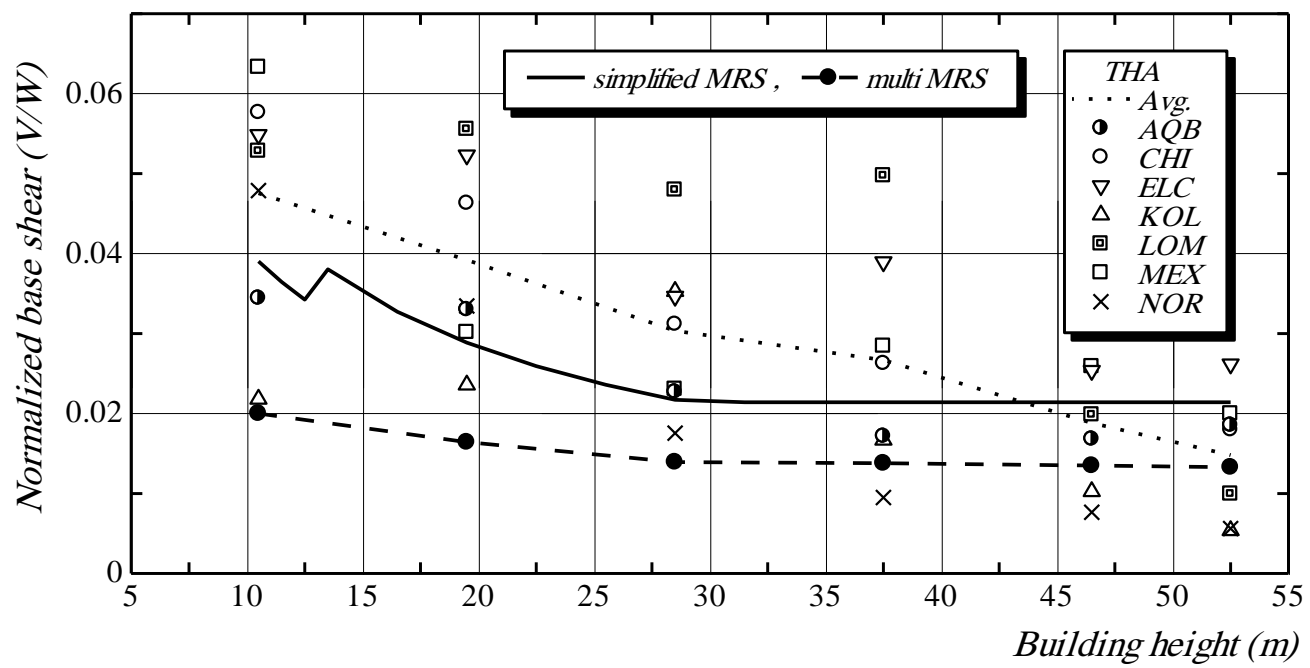

Fig. 5 : Normalized base shear due to different analysis methods (MRF building) 
The last presented investigation is carried out for SW-MRF buildings, similar observations are obtained except some differences which are to be discussed. Unlike the whole considered height range, the V/W obtained from simplified MRS is higher than the average of THA method for low buildings. The change is attributed to that at this height the code calculated period for SW-MRF building is 0.29 while it was 0.43 for MRF with same height and due to the nature of the used spectrum the obtained base shear is amplified at short periods. Thus, except this height the \% change in the V/W between the average THA and simplified MRS is in the range of $26.1 \%$ and $3.3 \%$. The $\%$ change in V/W between multi MRS and simplified MRS is higher than what was obtained for MRF buildings and of a range between $-36.3 \%$ and $-58.7 \%$. Regarding the \% change in results between average THA and MRS analysis is still high and in the range of $+62.1 \%$ and $+134.0 \%$. In closing, of these observations, the scaled Aqaba excitation is still yields the closest results to the simplified MRS method.

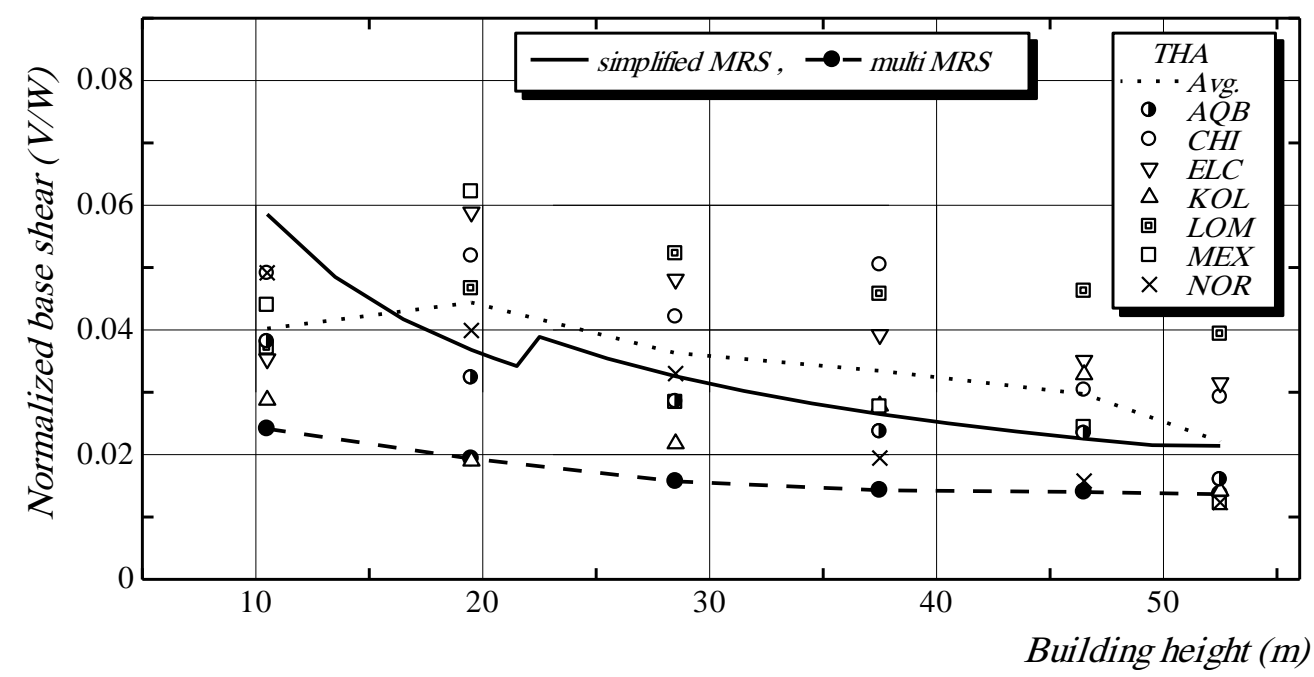

Fig. 6 : Normalized base shear due to different analysis methods (SW-MRF building)

As the 2008 ECOL considers the multi MRS analysis method as basis for design that is valid to all type of structure an due to the extremely low response obtained using this method in accordance with the other two methods an attempt is carried out to enhance the response obtained using this method. The reason for this highly underestimated behavior, at least in comparison with the simplified MRS, can be concluded in the long period obtained from modal analysis due to analyzing the structure as bare frame without considering the effect of masonry infill walls. This long period is supported by the rapid change in spectral reduction ductility factor which, in the assumed type 1 spectrum has high influence, to yield such extremely low response. In this relevance, most seismic codes limit the results obtained using the multi MRS to those obtained using simplified MRS. The 2008 ECOL does not provide such limitation although it was provided by the 1993 ECOL. The 1993 ECOL edition, as mentioned before, limit the forces obtained from the multi MRS to a minimum of $80 \%$ those obtained from the simplified MRS. Another way to enhance the results is the 
consideration of the effect of masonry infill walls. This is carried out for both MRF and SW-MRF buildings. The infill walls are assumed to occupy $60 \%$ of the total number of panels in every orthogonal direction. Masonry infill walls with commonly used $0.12 \mathrm{~m}$ thickness are used, modulus of elasticity of infill walls is assumed to be E $=5 \mathrm{GPa}$. Two models of infill walls are considered, the first is solid walls without any infills while the second considers central openings in the walls results in equivalent wall width of $60 \%$ the solid one. The infill walls are modeled using the methodology of equivalent strut method [23], the effect of the openings in masonry infill walls is considered relying on [24].

The results of $V / W$ for the MRF buildings are illustrated in Fig. 7. It can be concluded that the consideration of infill walls has a high influence on enhancing the V/W obtained from the multi MRS method. Comparing the results of the later method with the simplified MRS in its applicability height range (up to about $31.5 \mathrm{~m}$ ) it is found that the consideration of infill walls has high influence in enhancing the V/W especially for lower building heights. The $\%$ change in $\% \mathrm{~V} / \mathrm{W}$, relative to simplified MRS, does not exceed $-10.1 \%$ for solid wall model and $-20.3 \%$ for walls with opening model. Beyond this height limitation and as the building height increases the influence of infill walls vanishes. This is evident as at higher values of period the spectrum plateau is almost horizontal.

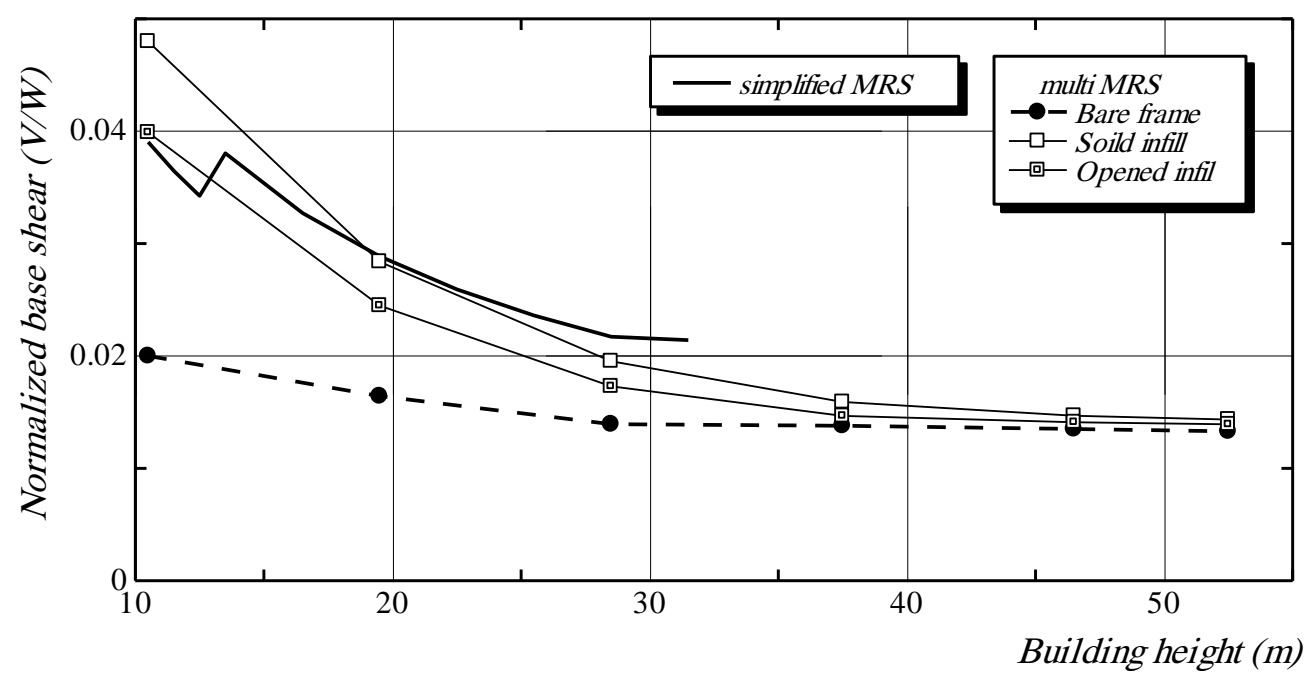

Fig. 7 : Effect of masonry infill wall consideration (MRF building)

Similar observations could be drawn out for SW-MRF buildings, but with different $\%$ change, the results of this structural system are depicted in Fig. 8. It could also be confirmed that the consideration of infill walls in the structural model is most influential for lower building heights. The obtained $\%$ change in $\mathrm{V} / \mathrm{W}$, relative to the simplified MRS, is in the range of $-18.5 \%$ to $-34.7 \%$ for the soil wall model and in the range of $-28.6 \%$ to $-40.1 \%$. Noting that the obtained values are for specific considered parameters of infill walls, different $\%$ change in the results could be obtained due to changing the infill parameters. 


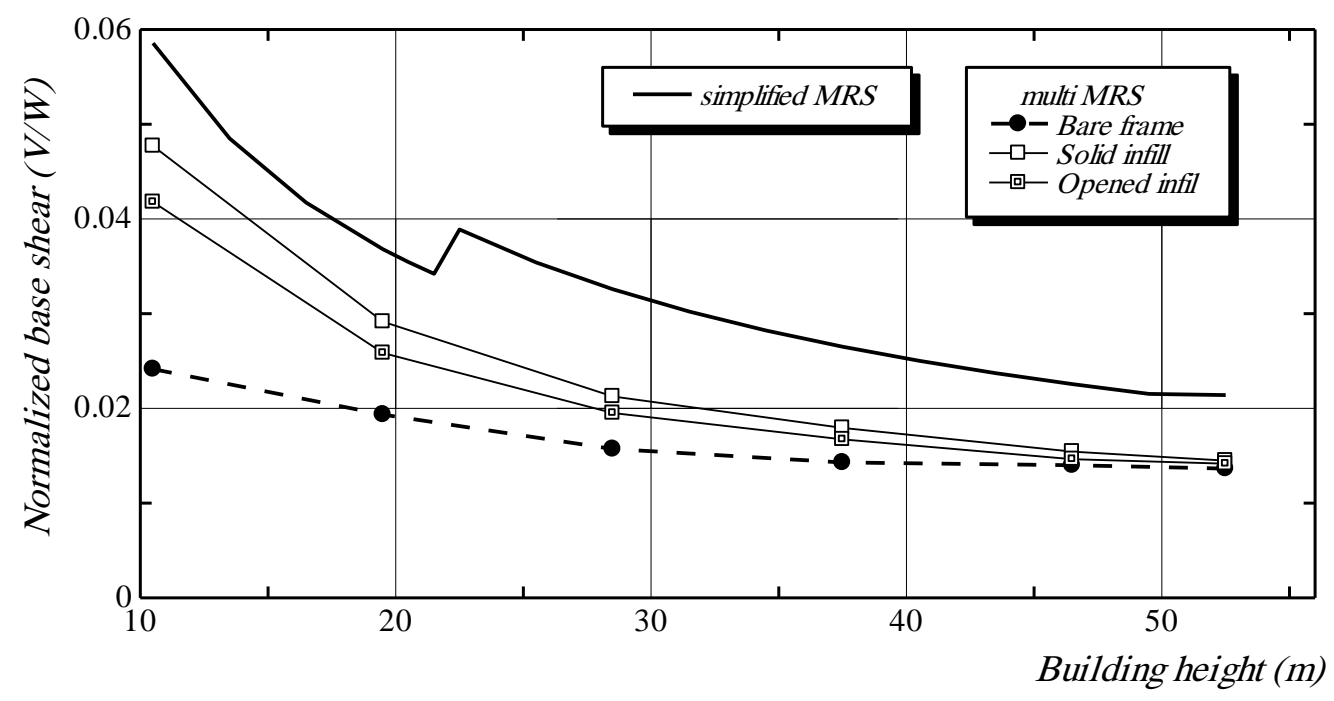

Fig. 8 : Effect of masonry infill wall consideration (SW-MRF building)

\section{SEISMIC PROTECTION LEVEL IN ECOL VERSUS OTHER CODES}

To verify the seismic protection level provided by the $2008 E C O L$ versus the results obtained from some different international codes, three seismic codes are selected. These codes include Eurocode- 8 , which is the basic referenced code to ECOL, the famous $U B C 97$ and Finally the recently renewed National Building Code of Canada $N B C C$.

For the sake of carrying out a rational comparison between these codes versus the recently edited 2008 ECOL, results obtained for buildings in Cairo city found on soil type $\mathrm{C}$ are compared with those for same building types found on same soil conditions and located in cities with seismicity similar to Cairo. Doing so, a city with zone factor $Z=0.15$ is selected to represent UBC 97 code while Kamloops city which is remarked by $\mathrm{PGA}=0.14 \mathrm{~g}$ is selected to represent the $N B C C$. Typical conditions to Cairo city are available in the Eurocode-8. The elastic response spectrum, which is constructed in regardless of the over strength factor, for the selected cities are illustrated in Fig. 9.

In this figure, Fig. 9, type 2 response spectrum is added for the sake of illustration. Some notes could be highlighted for this figure. These notes include the high proximity in the values of maximum spectrum acceleration between $E C O L$ with either spectrum types and the $U B C-97$. There is high correlation between the spectrum specified in type 2 ECOL spectrum and $U B C-97$. Also the maximum spectrum acceleration specified by the $N B C C$ is much less than all other code spectrum. Finally, the beginning of the descending spectrum curve is close between type $1 E C O L$ spectrum and the $N B C C$ and there is somehow correlation in the spectrum specified for the later two codes.

To get the design response spectrum from the elastic response one, all ordinates of spectral accelerations are divided by a factor used to incorporate for the 
inelastic response expected for the structure to the design earthquake. This factor is called response modification or force reduction factor $(R)$ in $2008 E C O L$, behavior factor in Eurocode-8 $(q)$, structural system coefficient $(R)$ in $U B C 97$ and overstrength and force modification factors $\left(R_{o} R_{d}\right)$ in $N B C C$. This factor depends mainly on the structural force resisting system (SFRS) and the proposed degree of ductility assumed for the building. Summary of values for response modification factor for MRF and SW-MRF buildings is shown in Table 2. A particular emphasis is to be carried out in this section to investigate the impact of this factor. It is worth to mention that this factor represents a major significant change between the seismic provisions in 2008 ECOL and Eurocode-8.

Table 2: Summary of response modification factor for MRF and SW-MRF buildings

\begin{tabular}{|l|c|c|c|c|c|c|}
\hline Structure system & \multicolumn{3}{|c|}{ MRF } & \multicolumn{3}{c|}{ SW-MRF } \\
\hline Ductility level & Low & Medium & High & Low & Medium & High \\
\hline ECOL & 5.0 & - & 7.0 & 5.0 & - & 6.0 \\
\hline Eurocode-8 & - & $3.3-3.9$ & $4.95-5.85$ & - & $1.8-3.6$ & $2.7-5.4$ \\
\hline UBC 97 & 3.5 & 5.5 & 8.5 & - & 6.5 & 8.5 \\
\hline NBCC & 1.95 & 3.5 & 6.8 & 1.95 & 2.8 & 5.6 \\
\hline
\end{tabular}

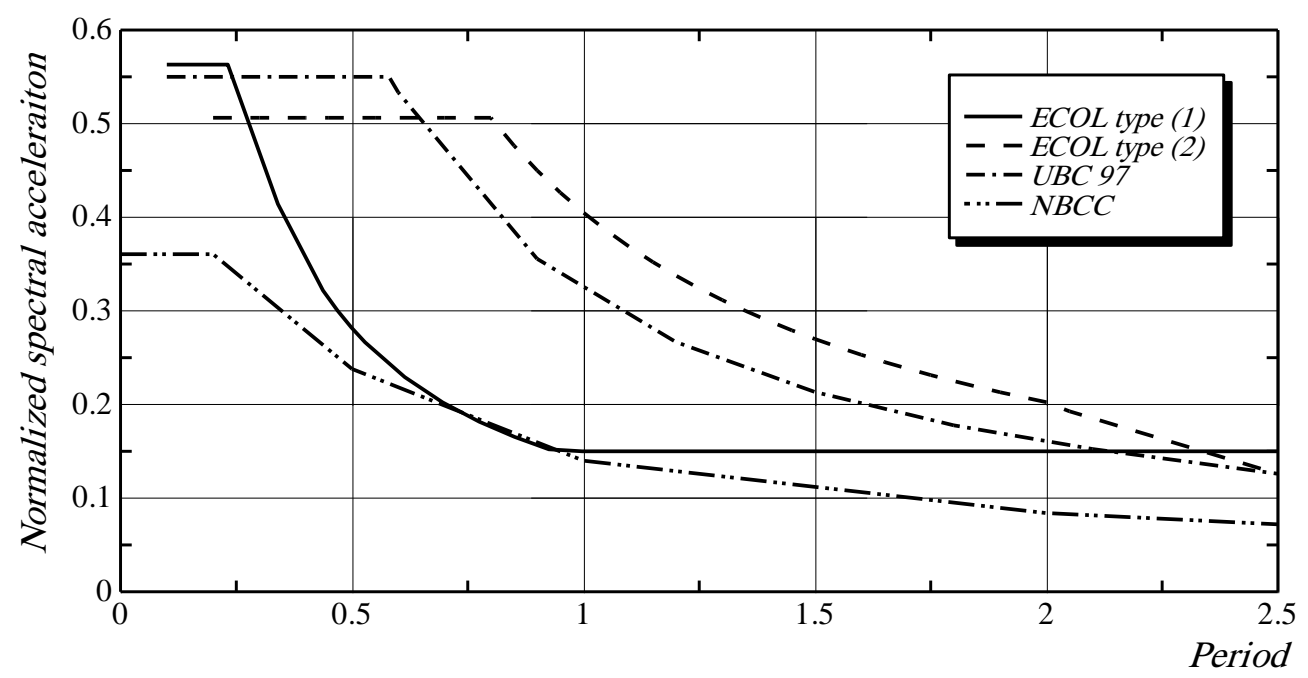

Fig. 9 : Normalized spectral acceleration for specified cities in different codes

As they need high attention in design, practically constructed in Egypt and to save space, the results obtained for structures with first lower degree of ductility are investigated and discussed. Results for any other degree of ductility can be easily obtained by scaling the results to the required degree of ductility. The obtained normalized base shear $V / W$ is calculated using both simplified and multi MRS analysis 
methods. The computer based results of the later method are obtained using the structures previously described in section 3 .

The results obtained for the MRF buildings using the different considered seismic codes are shown in Fig. 10. It can be noted that the obtained results of the normalized base shear can be arranged in the order, from the higher results to lower ones, according the following codes, UBC 97, NBCC, Eurocode- 8 and at last the $E C O L$. There is extreme variation in the results obtained from $U B C 97$ and $N B C C$, using either considered method of analysis, in comparison with the results obtained from the $E C O L$. The $\%$ change is higher for the results obtained utilizing the simplified MRS method. The \% increase in $\mathrm{V} / \mathrm{W}$, relative to the $E C O L$, ranges between $+108.6 \%$ to $+225.08 \%$ and from $+97.9 \%$ to $+154.55 \%$ utilizing $U B C 97$ and $N B C C$, respectively. Due to the fact that identical elastic spectrum is assigned for both ECOL and Eurocode-8, the variation in results is attributed the influence of the spectrum reduction factor. Thus the results obtained from Eurocode- 8 are higher than those obtained using ECOL by a ratio of about $+28 \%$. The results obtained utilizing the simplified MRS method are braced by those obtained using the computer bases multi MRS method. The last mentioned observations are valid but with different percentage ratios. The new \% ratios of increase range between $+66.6 \%$ to $+232.2 \%$ for $U B C 97$ and from $+54.7 \%$ to +158.1 for the Eurocode- 8 . These results indicate that the upper limit of \% change is close between the two method and that the \% change in the V/W is inversely relative to the building height.

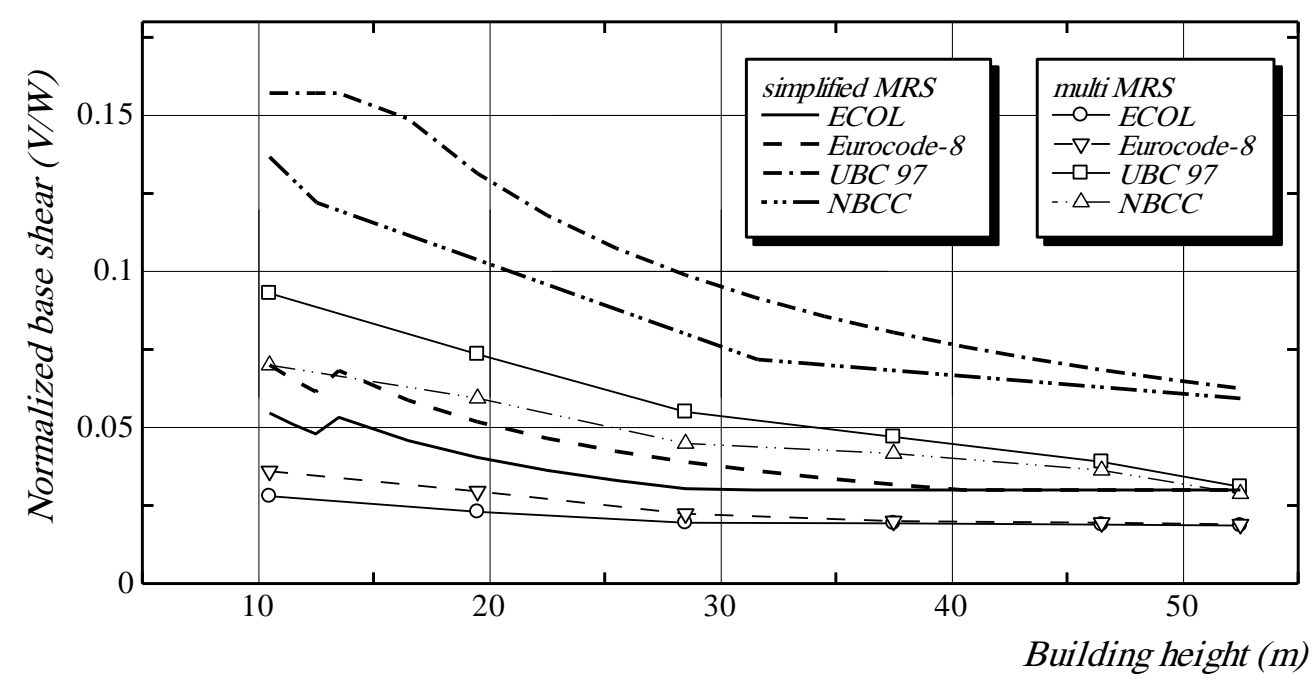

Fig. 10 : Normalized base shear according to different codes (MRF building)

The dual SW-MRF system is also investigated for the same lower ductility level. The code specified response reduction factors are 5.0, 6.5 and 1.95 for ECOL, UBC 97 and NBCC, respectively. This factor for dual systems, in the Eurocode-8, depends on the length of the shear walls and the building height. For the investigated building heights and the specified shear wall lengths, this factor decreases from 2.2 to 1.8 as the height increases from 10.5 to $52.5 \mathrm{~m}$. The results of both used methods 
utilizing the different considered codes are illustrated in Fig. 11. It can be observed that the highest \% change in the results are obtained for the NBCC and Eurocode- 8 which over most studied heights reveal close results. For these two codes, $\%$ increase, relative to $E C O L$, range between $+127.2 \%$ to $+177.8 \%$ and from $+103.9 \%$ to $+154.9 \%$ for the $N B C C$. The first ductility level in $U B C 97$ in case of dual SW-MRF buildings is shear walls with intermediate MRF ductility with $R$ coefficient of 6.5 . Thus, $\%$ change in results between $U B C 97$ and $E C O L$, decreases relative to the observed results of MRF buildings, to a range less than $+75.0 \%$. The $\%$ change in the V/W obtained from the $E C O L$ versus other codes are well matched to those obtained using the simplified MRS method with maximum difference less than $+6.0 \%$.

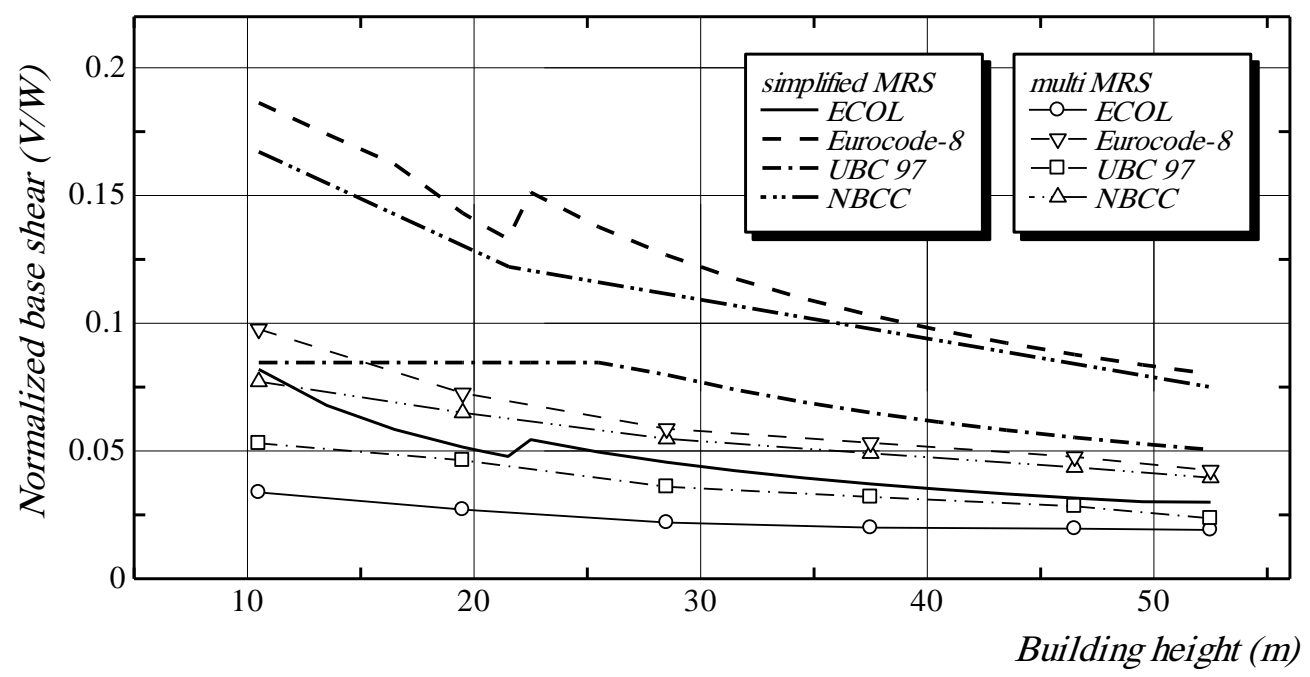

Fig. 11 : Normalized base shear according to different codes (SW-MRF building)

In closing of this section, the crucial effect of the response modification factor can be also illustrated through studying the change in normalized base shear of irregular MRF structures due to utilizing ECOL and Eurocode-8. Another motive for carrying out such investigation is to verify the results obtained using multi MRS for irregular structures. As mentioned before the 2008 ECOL restricts the application of simplified MRS analysis to irregular structures, hence utilizing either multi MRS or THA is mandatory.

As the same elastic spectrum is assumed for both two codes, the only difference in results will arise from assigning different response modification factors. While the $E C O L$ does not differentiate in the response reduction factor between regular and irregular structures, Eurocode-8 specifies a reduction of $20 \%$ in the response reduction factor in case of irregular buildings rather than regular buildings. So the resulting factor is 5.0 for ECOL and 3.12 for Eurocode-8. A multi MRS analysis is carried out, the results are shown in Fig. 12. It is clear that the variation in the value of response reduction factor between the two codes yields a $\%$ increase in the results, relative to the ECOL, up to $+60 \%$ for 3 floor buildings. The $\%$ change decreases as the building height increases to reach lower limit of $+6 \%$. 


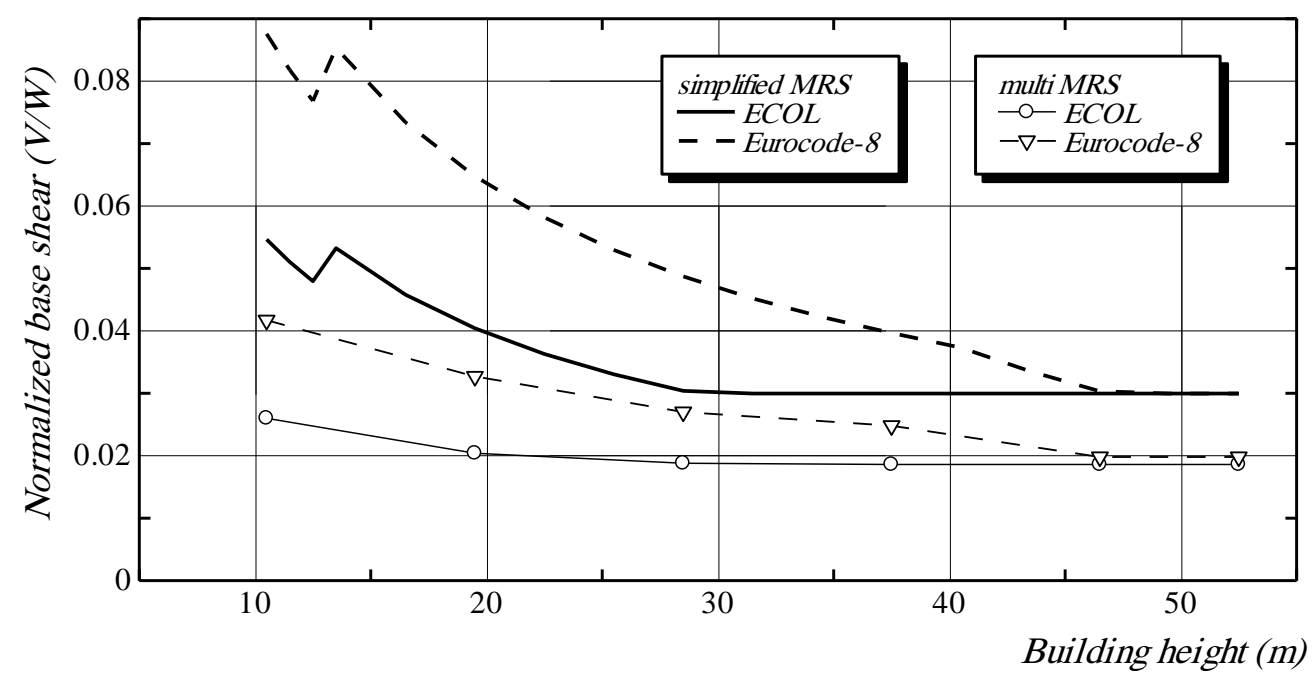

Fig. 12 : Effect of response modification factor on irregular buildings

\section{CONCLUSIONS}

A comparative numerical computer based multi MRS and THA using the code specified spectrum and seven deliberate earthquakes is carried out. The results of this numerical investigation are compared with the base shear calculated using the simplified MRS to assess and verify the impact of utilizing any of these methods and come up with required response enhancements. The normalized base shear calculated using the 2008 ECOL for buildings in Cairo city is compared with those obtained for similar cities using some international codes, a particular emphasis is paid to discuss the influence of response modification factor introduced in the 2008 ECOL. Relying on the investigations and discussions presented in this study, the following conclusions may be drawn out.

1) Extreme variation in the V/W obtained utilizing the three specified $2008 \mathrm{ECOL}$ analysis methods is observed. The computer based multi MRS method highly underestimate the obtained base shear in comparison with the other two methods especially for low to medium height buildings. This phenomenon is attributed to the high reduction in design spectrum associated with high periods and to the practically unconditioned modeling of structures as bare frames ignoring the effect of infills.

2) The consideration of infills especially for MRF buildings yields high correlation in results between simplified and multi MRS analysis.

3) Relying on the obtained results, it is highly required to recontemplate to modify the seismic provisions to scale the base shear obtained from multi MRS to those obtained relying on simplified MRS as the case in the previous 1993 ECOL and many other codes.

4) The response modification factor plays a crucial role in the obtained $V / W$. The $E C O L$ specifies, for most cases, the highest modification factor in comparison with the other considered codes as Eurocode-8 (main basis for ECOL), UBC 97 
and $N B C C$.

5) The simplified and multi MRS analysis carried out on cities match Cairo, in PGA and soil conditions, revealed that the normalized base shear obtained using the $E C O L$ was much less than the results obtained from other considered codes. The \% change in this dominator between ECOL and other codes could exceed $+230 \%$.

6) The influential effect of the response modification factor increases for irregular building in comparison with the reference code (Eurocode-8).

\section{REFERENCES}

1- " The Egyptian Code for Calculation of Loads and Forces in Structural and Building Work” Housing and Building Research Center, Cairo, Egypt, 1993.

2- "The Egyptian Code for Calculation of Loads and Forces in Structural and Building Work, ECOL 201 "Housing and Building Research Center, Cairo, Egypt, 2003.

3- " The Egyptian Code for Calculation of Loads and Forces in Structural and Building Work, ECOL 201 "Housing and Building Research Center, Cairo, Egypt, 2003.

4- Heidebrecht, A.C.: " Overview of Seismic Provisions of the Proposed 2005 Edition of the National Building Code of Canada " Can. J. Civ. Eng., Vol. 30, pp. 241-254, 2003.

5- Humer, J., Mahgoub, M.A.: “ Determination of Seismic Design Forces by Equivalent Static Load Method" Can. J. Civ. Eng., Vol. 30, pp. 287-307, 2003.

6- Saatcioglu, M., Humar, J.: “ Dynamic Analysis of Buildings for Earthquake Resistant Design" Can. J. Civ. Eng., Vol. 30, pp. 338-359, 2003.

7- Naeim, F.: “ The Seismic Design Handbook" Structural Engineering Series, Nan Nostrand Reinhold, 1989.

8- Arslan, M.H., Korkmaz, H.H.: “ What Is to Be Learned from Damage and Failure of Reinforced Concrete Structures During Recent Earthquakes in Turkey " Journal of Engineering Failure Analysis, Vol. 14, , pp. 1-22, 2007.

9- Eurocode-8: "Design of Structures for Earthquake Resistance " The European Committee for Standardization, Final Draft, December 2003.

10- Marino, M., Nakashima, M., Mosalam, K.: “ Comparison of European and Japanese Seismic Design of Steel Building Structures" Journal of Engineering Structures, Vol. 27, pp. 827-840, 2005.

11- Kaushik, H.B., Rai, D.C., Jain, S.K.: “ Code Approaches to Seismic Design of Masonry-Infilled Reinforced Concrete Frames: A State-of-the-Art Review " Journal of Earthquake Spectra, Vol. 22, pp. 961-983, 2006.

12- Kappos, A.J.: " Evaluation of Behaviour Factors on the Basis of Ductility and Overstrength Studies " Journal of Engineering Structures, Vol. 21, pp. 823-835, 1999.

13- Whittaker, A., Hart, G., Rojahn, C.: “ Seismic Response Modification Factors ” Journal of Structural Engineering, Vol. 125, No. 4, pp. 438-444, 1999. 
14-Genshu, T., Youngfeng, Z.: “ Inelastic Yielding Strength Demand Coefficient Spectra" Journal of Soil Dynamics and Earthquake Engineering, Vol. 28, pp. 1004-1013, 2008.

15- Haroun, M.A., Abdel Salam, M.N., Ismail,A.M.: " Fundamental Natural Period of Earthquake Resistant RC Buildings with Shear Wall Systems" Eleventh International Colloquium on Structural and Geotechnical Engineering, Egypt, 2005.

16- Abo El-Wafa, W.M.: " Effect of Masonry Infill Walls on the Natural Period of Reinforced Concrete Buildings" Journal of Engineering Science, Assiut University, Vol. 37, No.1, pp. 29-49, 2009.

17- Mwafy, A., Mahmoud, H.: " Performance of the Multi-Storey Structures Designed According to The Egyptian Provisions for Ductile Frame "Eleventh International Colloquium on Structural and Geotechnical Engineering, Egypt, 2005.

18-Megahed, A., Mahmoud, H.: " Performance of the Multi-Storey Structures Designed According to The Egyptian Provisions for Ductile Frame "Eleventh International Colloquium on Structural and Geotechnical Engineering, Egypt, 2005.

19- Abo El-Wafa, W.M.: “ Nonlinear Lateral Response of Masonry Infilled RC Buildings with Variable Parameter "Journal of Engineering Science, Assiut University, Vol. 37, No. 3, pp. 521-561, 2009.

20- Abo El-Wafa, W.M.: " Level of seismic protection in different editions of the Egyptian code of loads" Journal of Engineering Science, Assiut University, Vol. 37, No. 5, 2009.

21- " ETABS, Nonlinear version 9 Beta, Extended 3-D Analysis of Building Systems" Computers \& Structures, Inc., Berkeley, U.S.A., 2005.

22- "SAP 2000, Nonlinear version 11, Static and Dynamic Finite Elements Analysis of Structure" Computers \& Structures, Inc., Berkeley, U.S.A., 2007.

23- Mainstone, R. J.: " Supplementary Note on the Stiffness and Strength of Infilled Frames." Building Research Station, Garston, Watford, 1974.

24- Asteris, P.G.: " Lateral Stiffness of Brick Masonry Infilled Plane Frames" Journal of Structural Engineering, Vol. 129, No. 8, pp. 1071-1079, 2003.

\section{دراسة ويحث الطرق المختلفة لحساب الأحمال الزلزالية الجانبية}

نظرا لتعدد الطرق الواردة في الكود المصري للأحمال للحصول علي قيم قوي القص التصميمية

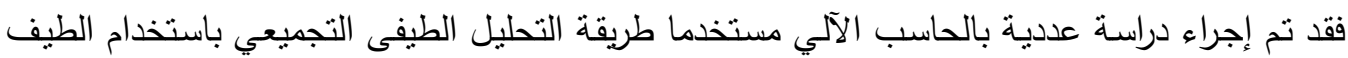
التصـميمي المقدم مـن الكـود المصـري (إصـدار سـبتمبر 2008) وطريقـة السجل الزمنـي الـديناميكي

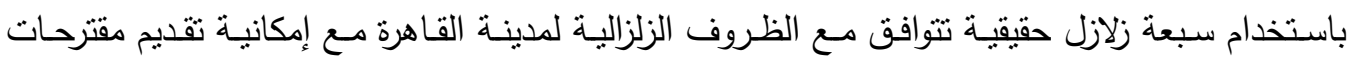

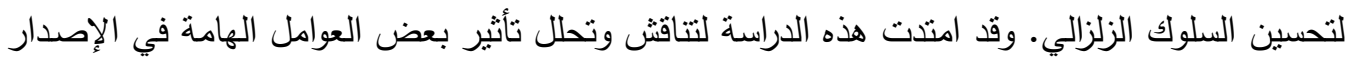
الأخير من الكود المصري للأحمال مثل معامل تعديل الاستجابة مقارنـة ببعض الأكواد العالمية مثل لهئل

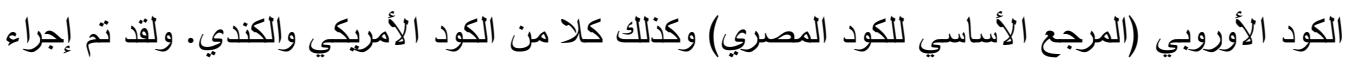


الدراسة العددية علي أنواع مختلفة من المباني مثل المباني ذات الإطارات المقاومة للعزوم وتلك التي لها

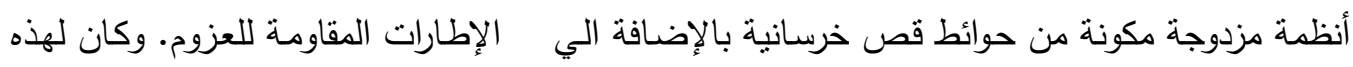

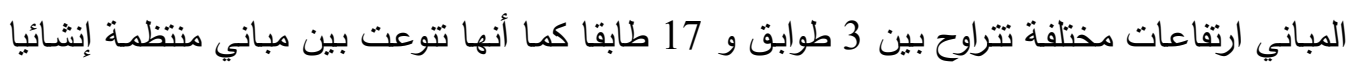

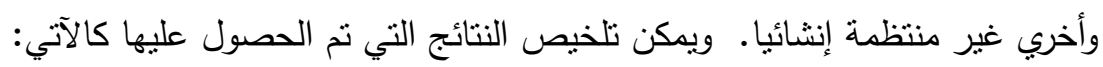

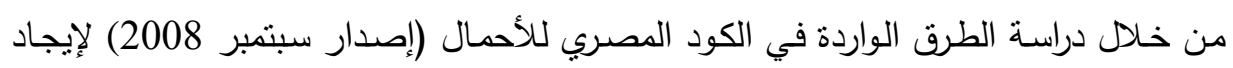

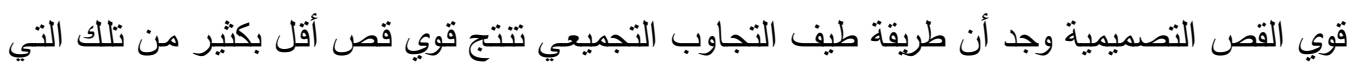

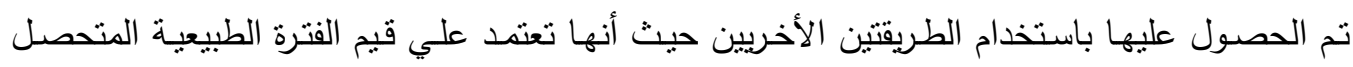

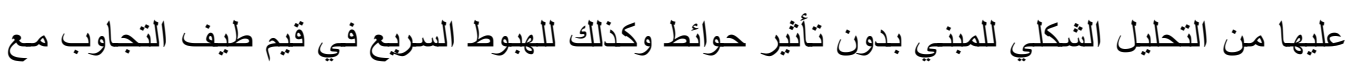

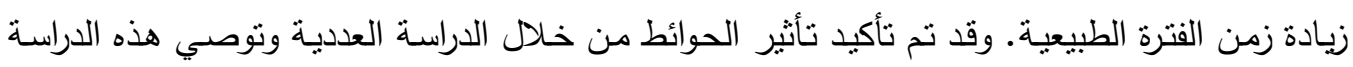

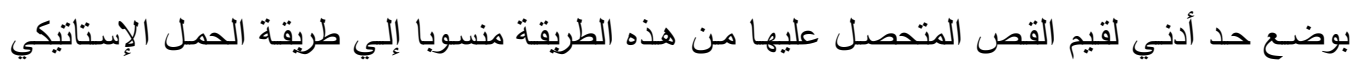
المكافئ مع استخدام معادلات الكود لحساب الفترة الطبيعية. وبدراسـة وتحليل معامل تعديل الاستجابة رالذي يعتمد في المقام الأول علي النظام الإنشائي

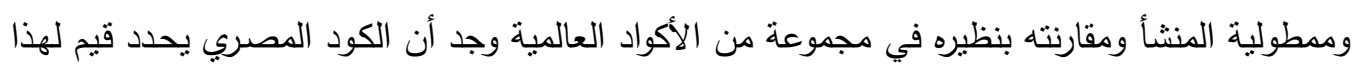

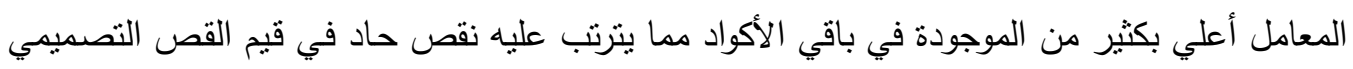
وقد تم تأكيد هذه النتائج من خلال دراسة المباني الغير منتظمة إنشائيا. 